East African Medical Journal Vol. 81 No. 4 April 2004

GASTROINTESTINAL INJURIES FROM BLUNT ABDOMINAL TRAUMA IN CHILDREN

E. A. Ameh, MBBS, FWACS, Senior Lecturer and Consultant Paediatric Surgeon and P. T. Nmadu, MBBS, FMCS (Nig), FWACS, Professor of Paediatric

Surgery, Paediatric Surgery Unit, Department of Surgery, Ahmadu Bello University Teaching Hospital, Zaria, Nigeria

Request for reprints to: Dr. E.A. Ameh, P. O. Box 76, Zaria, 810001, Nigeria

\title{
GASTROINTESTINAL INJURIES FROM BLUNT ABDOMINAL TRAUMA IN CHILDREN
}

\author{
E. A. AMEH and P. T. NMADU
}

\begin{abstract}
Objective: To determine the pattern, presentation and outcome of gastrointestinal injuries from blunt abdominal trauma in children.

Design: A retrospective study.

Setting: Ahmadu Bello University Teaching Hospital, Zaria, Nigeria.

Subjects: Twenty one children managed for gastrointestinal injuries from blunt trauma from 1984-2002.

Main outcome measures: The pattern, presentation, management and outcome of gastrointestinal injuries from blunt trauma.

Results: In the 19 year period, 1984-2002, 92 children were treated for blunt abdominal trauma, $21(23 \%)$ of who had injuries to the gastrointestinal tract. Three presenting after 24 hours had evidence of peritonitis. In six children with isolated gastrointestinal tract (GIT) injury who presented within two hours, abdominal signs were vague at initial evaluation but became marked over a few hours at repeated examination. In eight with associated intraabdominal injuries, abdominal signs were marked at initial examination and five presented with shock. Free peritoneal air was present on plain abdominal and chest radiograph in three of ten patients, dilated bowel loops in six and fluid levels in one. Diagnostic peritoneal lavage or paracentesis was positive in four patients with isolated GIT injuries and eight with associated intraabdominal injuries. There were 24 injuries in the 21 patients consisting of 15 perforations, five contusions, two seromuscular tears, and two gangrene from mesenteric injury. The small intestine was involved in 11 patients, colon six, stomach five, duodenum one and rectum one. Seven $(35 \%)$ patients had associated extraabdominal injuries. Treatment consisted of simple closure of perforations, over sewing of contusions, resection and anastomosis for gangrene and repair with protective stoma for the rectal injury. One patient each developed prolonged ileus, urinary tract infection and chest infection, respectively postoperatively. Mortality was $28 \%$, all of who had associated intraabdominal or extraabdominal injuries.

Conclusion: Gastrointestinal injury from blunt abdominal trauma in children, though uncommon, carries a high mortality, usually from associated intraabdominal or extraabdominal injuries.
\end{abstract}

\section{INTRODUCTION}

Trauma is gradually assuming importance in childhood morbidity and mortality pattern in developing countries. The pattern of blunt abdominal trauma in children in our environment has been documented(l). The management of blunt abdominal injury in children is now preferably non-operative, (2-4) but injuries to the gastrointestinal tract (GIT) may occur and will require laparotomy in majority of cases. The diagnosis of blunt GIT injuries becomes pertinent, as all efforts need to be made to avoid missing the injury. This report reviews the experience with blunt GIT injuries in Zaria, Nigeria.

\section{MATERIALS AND METHODS}

In the 19 year period, January 1984 - December 2002, 92 children aged $\leq 15$ years were managed for blunt abdominal trauma at the Ahmadu Bello University Teaching Hospital Zaria, Nigeria. Of these, 21(23\%) were confirmed intraoperatively to have gastrointestinal injury and have been retrospectively reviewed.

\section{RESULTS}

There were 16 boys and five girls, with an age range of 2 to 15 years (median 8.1 years) (Table I ). The cause of injury was road traffic accident in 11 patients (six pedestrians), falls seven and not documented in three. 
Presentation and evaluation (17 patients): The patients presented 30 minutes - 7 days (median 21/2 hours) after the injury. Clinical features at presentation in 17 patients are summarised in Table 2. Two patients with perforation and one with ileal gangrene presenting after 24 hours had evidence of peritonitis on admission. In six patients with isolated injury who presented within two hours, abdominal signs were vague at initial evaluation but became marked over a few hours at repeated examination. In the remaining patients, (all had associated intraabdominal injuries) abdominal signs were marked at initial assessment and five presented in shock. One patient with mesenteric injury and ileal gangrene and one with rectal injury passed blood in stool. One patient with gastric injury had haematemesis. One patient with mesenteric injury causing ileal gangrene and ileal perforation had intraabdominal abscess and presented with fever.

Plain abdominal and chest radiographs were documented in 10 patients. There was pneumoperitoneum in one patient with gastric perforation and subcutaneous emphysema in another with gastric perforation. There were dilated bowel loops in 6 patients ( 4 had isolated perforation) and fluid levels in one. Diagnostic peritoneal lavage (DPL) or paracentesis was positive in 4 patients with isolated perforation and in 8 patients with associated intraabdominal injuries. Gram stain of DPL or paracentesis fluid was not done in any patient.

Type of Injury (21 Patients): There were 24 gastrointestinal injuries in the 21 patients consisting of 15 perforations, 5 contusions, 2 gangrene from mesenteric injuries and 2 seromuscular tears. The specific sites and nature of injuries were as follows;

Stomach: The stomach was injured in 5 patients (23.8\% of gastrointestinal injuries and $5.4 \%$ of blunt abdominal trauma). There were 4 perforation; 2 on the anterior wall ofthe body and one each on the anterior aspect of the fundus and greater curvature respectively. One patient had contusion of the anterior wall of the body. One patient each had associated injuries to the pancreas, spleen and liver respectively. One with perforation also had a jejunal perforation and the patient with contusion had head injury in addition. The gastric perforations were repaired in 2 layers and the contusion over sewn. Associated injuries were treated accordingly.

Table 1

Age and Sex of 21 children with gastrointestinal injuries from blunt abdominal trauma

\begin{tabular}{llll}
\hline Age (years) & Male & Sex & Total $(\%)$ \\
\hline$<1$ & - & - & 0 \\
$1-4$ & 3 & - & $(0)$ \\
$5-9$ & 6 & 4 & $(14.2)$ \\
$10-15$ & 7 & 1 & $8(47.6)$ \\
Total & $16(76.2)$ & $5(23.8)$ & $(38.1)$ \\
\hline
\end{tabular}

Table 2

Features of gastrointestinal injuries from blunt abdominal trauma in 17 children

\begin{tabular}{llll}
\hline Feature & $\begin{array}{l}\text { Isolated } \\
\text { perforation } \\
(\mathrm{n}=9)\end{array}$ & $\begin{array}{l}\text { Associated } \\
\text { Intraabdominal Injury } \\
(\mathrm{n}=8)\end{array}$ & Total \\
\hline Abdominal pain & 9 & 8 & 17 \\
Abdominal tenderness & 9 & 8 & 17 \\
Abdominal distension & 7 & 7 & 14 \\
Vomiting & 7 & 4 & 11 \\
Pallor & 1 & 5 & 6 \\
Shock & 2 & 3 & 5 \\
Constipation & 1 & 1 & 2 \\
Haematochezia & 2 & - & 2 \\
Fever & 2 & - & 2 \\
Haematemesis & 1 & - & 1 \\
\hline
\end{tabular}

Table 3

Isolated gastrointestinal injuries in 13 children

\begin{tabular}{ll}
\hline Site & Number \\
\hline Ileum & 7 \\
Stomach & 2 \\
Jejunum & 1 \\
Rectum & 1 \\
Caecum/ascending colon & 1 \\
Stomach, ileum & 1 \\
\hline
\end{tabular}


Duodenum: One patient (4.7\% of gastrointestinal injuries and $1.1 \%$ of blunt abdominal trauma) had duodenal perforation. The pancreas and mesentery were also injured and there was a retroperitoneal haematoma. The duodenal perforation was repaired, the peritoneal cavity lavaged and drained. There were no associated extraabdominal injuries.

Small intestine: Eleven patients $(52.4 \%)$ of gastrointestinal injuries and $12 \%$ of blunt abdominal trauma) had injury to the small intestine (ileum eight, jejunum three). There were five ileal perforations (these were multiple in four patients), all isolated and within the last $25 \mathrm{~cm}$ of the ileum; one of these presented after seven days and had developed intestinal obstruction from adhesions and intraabdominal abscess. In two patients, a segment of ileum was gangrenous from transverse mesenteric laceration. The jejunal injuries were two perforations, one associated with gastric perforation and hepatic injury and one contusion associated with a gastric contusion and fracture of the humerus. Treatment was by segmental resection (four ileal perforations, two ileal gangrene from mesenteric injury), simple closure (two ileal perforations, two jejunal perforations) and over-sewing (one jejunal contusion). Associated injuries were treated accordingly.

Colon: Six patients $(28.6 \%$ of gastrointestinal injuries and $6.5 \%$ of blunt abdominal trauma) had colonic injuries, consisting of five contusions and one perforation. The specific sites of injury were transverse colon two (contusions, associated with liver injury and retroperitoneal haematoma and pancreatic injury respectively), sigmoid colon in two (one perforation associated with splenic injury and bladder contusion and one contusion), caecum one and ascending colon one. One patient had head injury in addition. Three contusions were over sewn, two left undisturbed and the sigmoid perforation was repaired. Associated injuries were managed accordingly.

Rectum: One patient had an intraperitoneal rectal perforation associated with retroperitoneal haematoma. The perforation was repaired and protected by a sigmoid colostomy.

Overall, 13 of 21 patients (61.9\% of gastrointestinal injuries and $14.1 \%$ of blunt abdominal trauma) had isolated gastrointestinal injuries (Table3).

Associated injuries: Overall, 8 of 21 patients (38.1\%) had 11 associated intraabdominal injuries to the spleen in three, pancreas three, liver two, reptroperitoneum in two and bladder one. Seven of 21 patients $(33.3 \%)$ had nine associated extraabdominal injuries including upper limb fractures in four, head injury three and lower limb fractures in two.

Morbidity and mortality: Three of 18 (16.7\%) patients developed complications. One patient with duodenal perforation had ileus lasting eight days, one patient with jejunal perforation developed urinary tract infection and a patient with sigmoid colonic injury had chest infection. The complications were managed by nasogastric tube suction and intravenous fluids and antibiotics respectively. The hospital stay of survivors was 12-24 days (median 15 days).

Mortality was five of $18(27.8 \%)$ patients. Three patients with gastric injury died, two from peritonitis and one from shock the former had associated injuries to the pancreas and spleen along with a fractured humerus and fractured tibia respectively, while the latter had associated head injury and fractured tibia. One patient with ileal gangrene from lacerated mesentery who had associated splenic injury, fractured humerus and head injury died from the head injury. A fifth patient with contusion of the transverse colon associated with hepatic injury, retroperitoneal haematoma and head injury died of shock. Overall, all five patients who died had associated extraabdominal injuries and three had associated intraabdominal injuries. Death occurred after 16 hours to 18 days (median 28 hours).

\section{DISCUSSION}

In this study, GIT injuries occurred in $23 \%$ of children with blunt abdominal trauma. Though one study (5) has noted that GIT injuries occur in $<1 \%$ of children following blunt abdominal trauma, the rate of GIT perforation is $4.3 \%-8.5 \%$ in most reports(6-8). In the present study, the rate of GIT perforation following blunt abdominal trauma was $16.3 \%$, but the number of our patients was small. As in other studies (5-7) most of the injuries resulted from road traffic accidents and falls.

Most patients in this study presented with abdominal pain, tenderness and distension, however, the features were vague at initial examination in patients with isolated injuries and became obvious only at repeated abdominal examinations. Evidence of peritonitis was present in patients presenting after 24 hours of injury. Marked abdominal sign and shock were present in patients with associated injuries to other intraabdominal organs. In one report(6) though distension was present in $50 \%$, only $38 \%$ had general abdominal-tenderness, while in another study (7), 54\% had evidence of peritonitis, $29 \%$ guarding and $26 \%$ minimal tenderness. Due to vague features, diagnosis of GIT injury may be delayed, $(5,6)$ but multiple perforation may correlate with earlier signs of peritonitis(7). Of 10 patients in this study, only three had evidence of pneumoperitoneum on plain abdominal radiography and the remaining had non-specific features such as dilated bowel loops and fluid levels. Other studies have noted pneumoperitoneum in $8.5 \%-46 \%$ of patients(6-8). Computed tomography (CT) scan may be useful in detecting clinically significant intestinal or mesenteric injury(9) and may show specific features of GIT perforation such as free air and localized low density fluid(10). Though one study has noted a high sensitivity, specificity and negative predictive value with CT scan, (9) the positive predictive value was low and may result in unnecessary laparotomy. 
Intestinal injuries may be missed by CT scan(10) and CT scan detected free air may not be due to GIT perforation but may result from pneumothorax or mechanical ventilation(11). CT scan results must therefore be correlated with the patient's clinical condition. CT scan is not readily available in our environment. Other investigations such as diagnostic peritoneal lavage may be useful and elevated serum amylase may be suggestive(6). In one study, (7) elevated transaminases and white blood cell were significantly higher in patients with peritonitis compared to those with minimal or normal findings. At the present time, the management of blunt abdominal trauma in children was preferably non-operative but GIT injury may be missed(12,13). Since obvious features may not be present at initial examination and the result of investigations often non-specific, the diagnosis of GIT injury requires repeated examination and a high index of suspicion.

As in other studies, $(5-7,14,15)$ the small intestine was most commonly injured in the present study but gastric injury was particularly frequent. Associated intraabdominal and extraabdominal injuries were frequent in these patients. Simple closure is usually adequate for single perforation of the stomach and small intestine $(6,7,14)$ but more extensive injuries such as multiple perforations and gangrene from mesenteric injury may require resection and anastomosis. Large bowel injures, particularly in the left colon may require creation of stoma.

The mortality in this study was high at $27.8 \%$ but all the patients had associated intraabdominal or extraabdominal injuries. Mortality in other studies (5$7,14)$ is $1.8 \%-7.6 \%$ and was usually due to associated injuries.

\section{ACKNOWLEDGEMENTS}

To Professors O. A. Mabogunje and J. T. Momoh whose patients were included in this study and the medical records department of A.B.U. Teaching Hospital, Zaria for providing the records.

\section{REFERENCES}

1. Ameh, E. A., Chirdan, L. B. and Nmadu, P. T. Blunt abdominal Trauma in children: epidemiology, management and management problems in a developing country. Pediatr. Surg. Int. 2000; 16:505-509.

2. Peclet, M. and Murphy, J. P. Abdominal and urinary tract trauma. In: Ashcraft K. W., Holder, K. M. (eds). Pediatric Surgery. Saunders, Philadelphia, 1993; 133-140.

3. Keller, M. S. and Vane, D. W. Management of paediatric blunt splenic injury: comparison of paediatric and adult trauma surgeons. J. Pediatr. Surg. 1995; 30:221-225.

4. Yoo, S., Lim, K., Kang, S. and Kim, C. Pitfalls of nonoperative management of blunt abdominal trauma in children in Korea. J. Pediat. Surg. 1996; 31:263-366.

5. Canty, T. H., Sr., Canty, T. G. Jn. and Brown, C. Injuries of the gastrointestinal tract from blunt trauma in children: a 12-year experience at a designated trauma center. J. Trauma 1999: 46:234-240.

6. Brown, R. A., Bass, G. H., Rode, H., Miller, A. J.W., and Cywes, S. Gastrointestinal tract perforation in children due to blunt abdominal trauma. Brit. J. Surg. 1992; 79: 522524.

7. Ciftci, A. O., Tanyel, F. C., Salman, A. B., Buyukpamukcu, N. and Hicsonmez, A. Gastrointestinal tract peroration due to blunt abdominal trauma. Pediatr. Surg. Int. 1998; 13:259-264.

8. Albanese, C. T., Meza, M. P., Garner, M. J., Smith, S. D., and Rowe, M. I. Is computed tomography a useful adjunct to the clinical examination for the diagnosis of paediatric gastrointestinal perforation from blunt trauma in children? J. Trauma 1996; 40:417-421 .

9. Graham, J. S. and Wong, A. L. A review of computed tomography in the diagnosis of intestinal and mesenteric injury in paediatric blunt abdominal trauma. J. Pediat. Surg. 1996; 31:754-756.

10. Sarihan, H. and Abes, M. Non-operative management of intraabdominal bleeding due to blunt trauma in children: the risk of missed associated injuries, Pediatr. Surg. Int. 1998; 13:108-111

11. Sjovall, A. and Hirsch, K. Blunt abdominal trauma in children: risks of non-operative treatment. J. Pediatr. Surg. 1997; 32: 1169-1174

12. Ulman, I., Avanoglu, A., Ozcan, C., Demircan, M., Ozok, G. and Erdener, A. Gastrointestinal perforation in children: a continuing challenge to non-operative treatment of blunt abdominal trauma. J. Trauma. 1996; 41:110-113.

13. Miyakawa, K., Kaji, T., Wakabayashi, M., et al. CT of intestinal injuries following blunt trauma (Abstract) Nippon Igoku Hoshasen Gakkai Zasshi. 1992; 52:1653-1660.

14. Kane, N. M., Francis, I. R., Burney, R. E., et al. Traumatic pneumoperitoneum. Implications of computed tomography diagnosis (Abstract). Inves. Radiol. 1991; 26:574-578.

15. Grosfeld, J. L., Rescorla, F. J., West, K. W. and Vane, D. W. Gastrointestinal injuries in childhood: Analysis of 53 patients. J. Pediat. Surg. 1989; 24:580-583.

16. Sherck, J. P. and Oakes, D. D., Intestinal injuries missed by computed tomography. J. Trauma 1990; 30:1-7. 